Article

\title{
An Experimental Study on the Effects of Atomized Rain of a High Velocity Waterjet to Downstream Area in Low Ambient Pressure Environment
}

\author{
Dan Liu ${ }^{1}$, Jijian Lian ${ }^{1,2}$, Fang Liu ${ }^{1, * \mathbb{D}}$, Dongming Liu ${ }^{1}$, Bin Ma ${ }^{1}$ and Jizhong Shi ${ }^{3}$ \\ 1 State Key Laboratory of Hydraulic Engineering Simulation and Safety, Tianjin University, Tianjin 300350, \\ China; Liudan_Hydraulic@tju.edu.cn (D.L.); jjlian@tju.edu.cn (J.L.); hpeliudm@tju.edu.cn (D.L.); \\ mabin97@tju.edu.cn (B.M.) \\ 2 School of Water Conservancy and Hydroelectric Power, Hebei University of Engineering, \\ Handan 056038, China \\ 3 Zhejiang East China Engineering Consulting co. LTD of PowerChina Huadong Engineering Corporation \\ Limited, No.201 Gaojiao Road, Yuhang District, Hangzhou 311122, China; shihu286@163.com \\ * Correspondence: fangliu@tju.edu.cn; Tel.: +86-155-1081-0907
}

Received: 23 December 2019; Accepted: 31 January 2020; Published: 1 February 2020

\begin{abstract}
A better understanding of the atomized rain characteristics in low ambient pressure areas is beneficial in reducing the jeopardizing effect of flood discharge atomization on high-altitude hydropower stations. A random splash experiment is designed with two measurement planes to investigate the effects of low ambient pressure on downstream atomized rain under the complicated conditions of low ambient pressure (within $0.60 P_{0} \sim 1.00 P_{0}$ ) and high waterjet velocity (at a magnitude of $10 \mathrm{~m} / \mathrm{s}$ ). The results demonstrate that the atomized rain (rain intensity $\geq 2 \mathrm{~mm} / \mathrm{h}$ ) downstream, characterized by two-dimensional distribution, can be enhanced by decreasing the ambient pressure and by increasing the inflow discharge. When the ambient pressure decreases at the same inflow discharge, both the distance of the rain intensity lines $(40 \mathrm{~mm} / \mathrm{h}, 10 \mathrm{~mm} / \mathrm{h}, 2 \mathrm{~mm} / \mathrm{h})$ in the horizontal plane from the constricted nozzle outlet and the average rain amount in the inclined plane within the atomized source ratio of $\left((0 \sim 30) \times 10^{-3}\right) \%$ appear as "linear" growth. With the ambient pressure decreasing by $0.10 P_{0}$, the range of those characteristic rain intensity lines is expanded by $0.68 \% \sim 1.37 \%$, and the average rain amount is enlarged by $11.06 \% \sim 20.48 \%$. When keeping the low ambient pressure unchanged, both the point average rain intensity reduction along the releasing centerline and the surface average rain amount growth with increased inflow discharge all follow an exponential function. The aeration reduction in the waterjet boundary and the resistance reduction in atomized water-droplets are contributing factors for the enhancement effect of low ambient pressure. This study can enable the establishment of a foundation to further predict flood discharge atomization in a high-altitude environment.
\end{abstract}

Keywords: low ambient pressure; random splash experiment; atomized rain; downstream spatial distribution; rain intensity

\section{Introduction}

As fundamental infrastructure components of flood control and energy development systems, many large hydraulic projects have been constructed or are under construction globally [1-3]. The flood discharge security of these projects largely depends on the reasonable design of releasing structures and security regulations suitable for discharge environments [4]. Changes in the local meteorological environment induced by atomized flow during flood discharge are commonly manifested as super-heavy rain and widespread mist—namely, flood discharge atomization. This situation can 
be seen from Jinping-1 Hydropower Station in Figure 1, where, under different energy dissipation conditions, the atomized rain intensity has been measured as high as $534 \mathrm{~mm} / \mathrm{h}$ when induced by dam orifice discharging $\left(Q=4100 \mathrm{~m}^{3} / \mathrm{s}, 2 \# / 4 \#\right.$ deep orifices and 2\#/3\# surface orifices in Figure 1a) and up to $331 \mathrm{~mm} / \mathrm{h}$ when induced by spillway tunnel discharging $\left(Q=2130 \mathrm{~m}^{3} / \mathrm{s}\right.$, gate opening of $75 \%$ in Figure $1 b$ [5]. In surveying global studies on atomized flow, it is found that most flood discharge atomization occurs in China, especially for hydropower stations with ski-jump energy dissipation characterized by high heads, high discharge and deep canyons. It has been widely recognized that hazard sources arise from strong atomized rain, and major atomized rain sources are generated by aerial waterjet collisions and the hydraulic impact of falling waterjets into a water cushion [6]. With approximately 30 years of progressive research, the damages caused by strong atomized rain have been greatly reduced, but they still occur occasionally, such as the severe landslides at the Longyangxia Hydropower Station in 1987 and 1989 due to its soft geology and arid climate [7], the unexpectedly high level of atomized rain at the Ertan Hydropower Station due to a high energy dissipation ratio with aerial waterjet collisions in 1998 [8], the rare rainstorm disaster of the Shuibuya Hydropower Station formed by the combination of atomized and natural rain in 2016 [9], and the flood at the Nazixia Hydropower Station Powerhouse due to unreasonable design in 2017 [10]. Moreover, the slip square has reached 81 million $\mathrm{m}^{3}$ in the "1989.7.26" slope instability of the Longyangxia Hydropower Station [7], and the direct economic loss has reached about 50 million yuan for the "2016·7·19" flood event of the Shuibuya Hydropower Station [9]. From the above, we can see that such strong precipitation events probably led to a variety of direct damages and secondary disasters such as those resulting from extreme natural rain events, which can bring more severe economic and environmental consequences with characteristics of the new age [11,12]. To minimize production and living damage, partition protections have been acknowledged as a mitigation strategy according to rain thresholds based on precipitation forecast results. Therefore, predicting and controlling flood discharge atomization is a long-term goal, especially for projects with unique structures or complex designs. Furthermore, due to both generation and diffusion processes of atomized rain containing complicated water-air interactions, the low ambient pressure environment possibly affects the atomization processes to a varying degree, which will increase the uncertainty of the prediction of the distribution of rain atomization. The challenge of flood discharge atomization increases because some hydropower stations with ski-jump energy dissipation are constructed and operated in areas with low air density. For example, the ambient pressure of the Rumei spillways is only $73.53 \mathrm{kPa}$, which means the operating pressure is only 0.72 that of the standard pressure $P_{0}(101.53 \mathrm{kPa})[5,13]$.

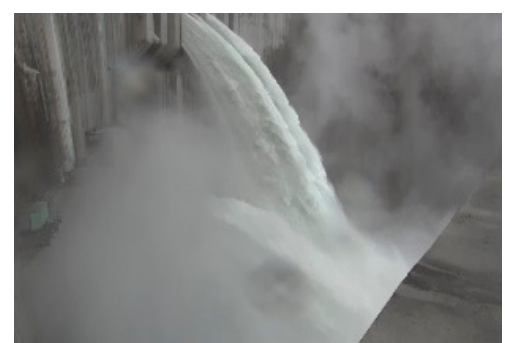

(a)

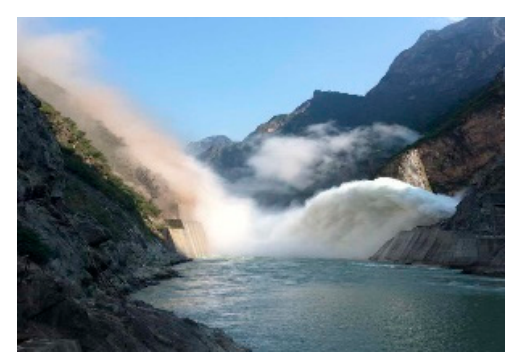

(b)

Figure 1. Prototype observation of flood discharge atomization in Jinping-1 Hydropower Station. (a) Flood discharge atomization induced by the release from dam orifices; (b) Flood discharge atomization induced by the release from a spillway tunnel.

In an attempt to avoid and reduce the negative effects of strong atomized rain, the prediction and classification of atomized rain have attracted considerable attention. In order to accurately predict the intensity of atomized rain, the random splash models are proposed to explore the atomization mechanism and have been successfully applied in projects [10,14-16]. More specifically, the random splash models derive from a better insight into prototypical atomized sources. Different from scale 
tests designed by the gravity similarity criterion according to individual projects, the random splash models focus on common factors of atomized rain without thinking about scale effects. In practice, the distribution of atomized rain arising from random splash models are used for the qualitative analysis and quantitative prediction of uncertainty factors, and eventually, the main influencing factors and influencing modes of atomized rain can be identified by introducing random functions. However, the atomized rain intensity arising from the scale tests needs to be corrected by statistical law, and then the degree and area of atomized rain can be described by a geometric scale depending on the corrected rain intensity [5]. Liu et al. [17] measured rain intensity distribution splashed by high-velocity waterjets with velocities of 37.08 m/s, 52.40 m/s and 58.59 m/s. Liu et al. [15], Liu et al. [18], and Lian et al. [19,20] carried out diverse random splash experiments induced by a single waterjet with relatively low velocities. In such experiments, the distribution law of point average rain intensity is used to explore the formation of the random splash source and the influence mechanism of the atomized rain field, which is introduced in the application of the parameter calibration for numerical models to predict the full-scale distribution of atomized rain in prototype engineering [14-16]; the distribution law of surface average rain amount is designed to explore the relationship between inflow hydraulic conditions and localized atomized rain, which has been qualitatively extended to analyze the impact and protection design in local area [10]. The random splash process can be divided into three steps [15,18-20]. First, when the aerated waterjet comes into contact with the water cushion, a great impact force is produced, similar to solid crashes. Subsequently, part of the water splashes out, further breaking under the action of nappe wind. Finally, variable-size atomized water-droplets spread downstream and converge on a solid surface. That is, the stochastic splash is of macroscopic splash characteristics with an enormous number of water-droplets, which is different from applications in other fields, e.g., forest fire fighting (liquid droplets impinging on a solid surface) [21], pesticide spraying (liquid droplets impinging on leaf surface) [22], diving (a solid falling into a liquid surface) [23], wind-driven rain erosion (rain droplets driven by high-speed wind impinging on building facades) [24], rain-wind-induced vibrations (rain droplets driven by high-speed wind impinging on beam or rope structures) [25], vehicle soiling and aircraft icing problems (droplets impinging on a high-speed moving boundary) [26], etc. Currently, all random splash models are conducted under atmospheric pressure with particular emphasis on various hydraulic conditions of inflow waterjets. Nevertheless, environmental conditions like ambient pressure have not been systematically considered and studied [5], even though the splash in particular is likely to be influenced by low ambient pressure in the course of waterjet aeration and atomized water-droplets diffusion [27-31].

In high-altitude areas, the decrease in air density can reduce the ambient pressure, which generally results in low ambient pressure effect in many fields. To assess the low ambient pressure effect, it is helpful to conduct a relevant experiment in an artificial low-pressure environment. Depressurized chambers have been applied to mechanism research and practical applications in many related fields. In the study of water mist and water-droplets, Cai [32] discovered that the water mist tends to gather towards the conical surface under operating conditions of reduced ambient pressure $\left(<P_{0}\right)$ and constant nozzle pressure; Wang et al. [33] found that the mean diameters of water mist decrease as the ambient pressure decreases $\left(<P_{0}\right)$ under conditions with the same working pressure of water mist system, while axial velocities of water mist droplets are affected by the ambient and system working pressure; Tsai et al. [34] indicated that there is a dry area at the collision center that can trap an air mass after an ethanol drop (millimeter-sized) impacts a solid wall, and a lower ambient pressure leads to a smaller splash; Mitchell et al. [35] presented droplet splash experiments using 3.5mm diameter ethanol droplets discretely impacting on metal surfaces at $4 \mathrm{~m} / \mathrm{s}$, in which the impulse and peak force of collisions were slightly higher in low ambient pressure $(23.3 \mathrm{kPa})$ than in stranded pressure $(101 \mathrm{kPa})$ despite the lower ambient pressure significantly reducing the corona splash; Latka et al. [36] analyzed the inhibiting effects of surface roughness and environmental pressure, such that the splash can be suppressed under low ambient pressure conditions with very rough surfaces and the splash can be produced under high ambient pressure conditions with relatively smooth surfaces; Burzynski et al. [37] expounded that the 
angle and number of secondary droplets are affected by the surrounding gas, but the size distribution and horizontal velocity are not affected by the impacting course of a droplet and a smooth dry glass surface. Hence, low ambient pressure has a high potential to impact the movement of atomized rain droplets. Speaking of hydraulic model experiments, experimental results indicate that decreasing the ambient pressure can lead to a decrease in gas nuclei and an increase in the surface tension coefficient of the still water, and meanwhile can enhance the dynamic pressure of a plunge pool floor [30]. Hence, the low ambient pressure probably affects the flood discharge security of high-altitude hydropower stations. However, systematic research results remain rare, especially in the field of flood discharge atomization generated by high-velocity modeling waterjets [5].

Therefore, it is urgent to carry out a random splash experiment associated with low ambient pressure to meet the demand of flood discharge atomization protection in high-altitude hydropower stations. In this paper, a random splash experiment is designed in a depressurized chamber to evaluate the effects of low ambient pressure on downstream atomized rain splashed by a high-velocity waterjet. In detail, the regulation of the stable gas-water coupling environment and the measurement of atomized rain in the restricted closed environment will be introduced. The experimental results of atomized rain distribution and relevant factors will be discussed and analysed.

\section{Experimental Setup and Measurements}

\subsection{Design and Regulation of Experimental Platform}

The experiment was conducted on a two-phase experimental platform characterized by high flow velocity and low ambient pressure at the State Key Laboratory of Hydraulic Engineering Simulation and Safety of Tianjin University. The high velocity of the waterjet was created by a jet pump and a constricted nozzle. The low pressure in the depressurized chamber was regulated by a vacuum pump and a sealed air tank. The time-averaged point rain amount in a horizontal plane and the space-averaged surface rain amount in an inclined plane were designed as the measurement parameters. Figure 2 describes the physical diagram and partial design of the experimental platform, including the layout of the depressurized chamber (Figure 2a), the layout of the constricted nozzle (Figure 2b), the point rain collection and the measurement device of the horizontal plane (Figure 2c) and the surface rain collection and the measurement device of the inclined plane (Figure 2d).
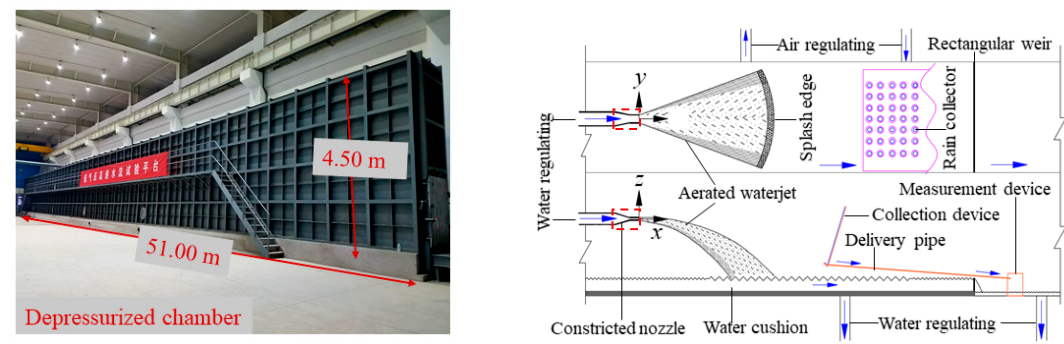

(a)
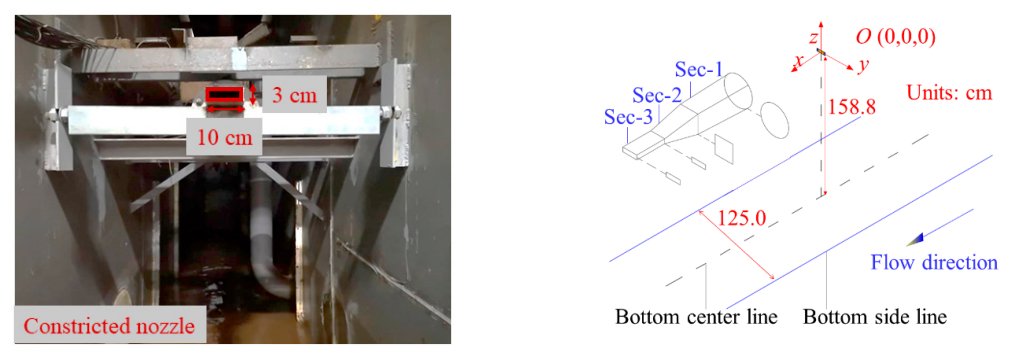

(b)

Figure 2. Cont. 

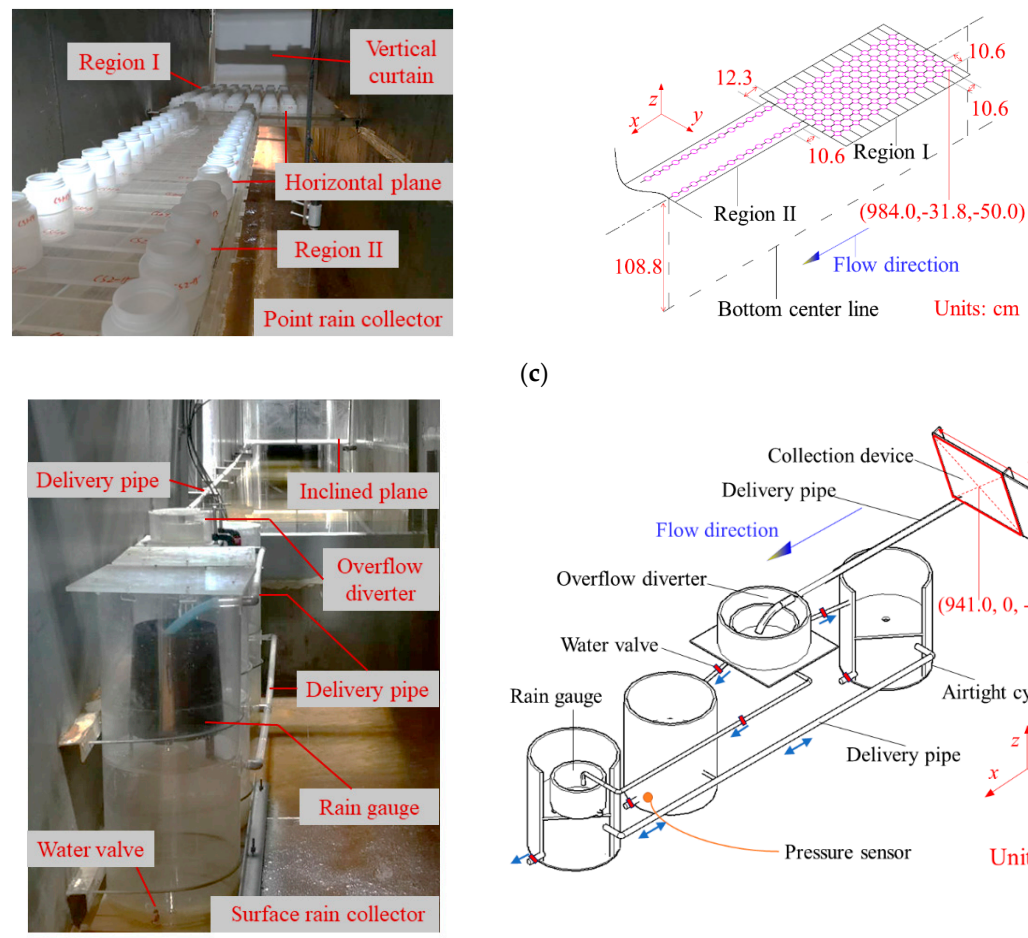

(c)

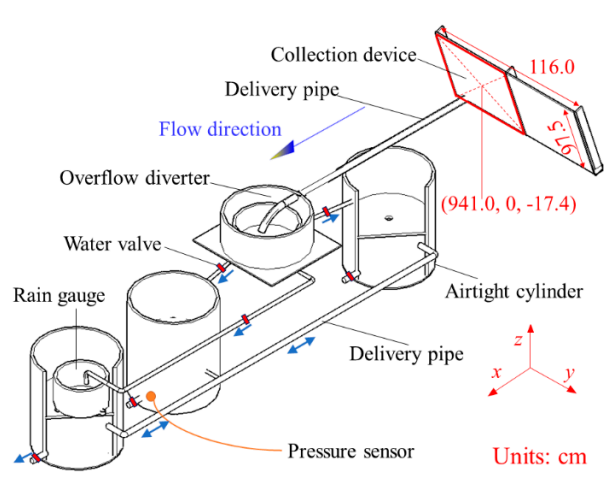

(d)

Figure 2. Physical diagram and partial design of the experimental platform. (a) Depressurized chamber layout; (b) Constricted nozzle layout; (c) Point rain collection and measurement device of the horizontal plane; (d) Surface rain collection and measurement device of the inclined plane.

As shown in Figure 2a, the depressurized chamber was designed as a cuboid with an internal volume of $51.00 \mathrm{~m}$ (length) $\times 4.50 \mathrm{~m}$ (height) $\times 1.25 \mathrm{~m}$ (width). The water-regulating and air-regulating devices were installed outside the depressurized chamber. In the depressurized chamber, a coordinate system was built by taking the center point of the constricted nozzle outlet as the coordinate origin, in which the $x$-axis, $y$-axis, and $z$-axis separately represent the flow direction, transverse direction, and vertical direction; the experimental area is $1487 \mathrm{~cm}$ long along the flow direction, which is surrounded by the depressurized chamber walls and a rectangular weir $(125 \mathrm{~cm}$ in width and $56 \mathrm{~cm}$ in height).

As a classic fluid problem [38-40], the rectangular waterjet also plays an important role in the research on flood discharge atomization [14]. Therefore, the constricted nozzle was designed with a rectangular outlet, including three sections along the flow direction: Section 1 is a circle-to-square transition region for connecting the upstream water pipe $(D=20 \mathrm{~cm})$, Section 2 is a contraction section ( $12.50 \mathrm{~cm}$ wide $\times 12.50 \mathrm{~cm}$ high to $10.00 \mathrm{~cm}$ wide $\times 3.00 \mathrm{~cm}$ high) for improving the velocity, and Section 3 is a rectifying section $(10.00 \mathrm{~cm}$ wide $\times 3.00 \mathrm{~cm}$ high) for producing a regular waterjet; the sections are $30.00 \mathrm{~cm}, 25.00 \mathrm{~cm}$, and $20.00 \mathrm{~cm}$ long, respectively, as shown in Figure $2 \mathrm{~b}$.

Within experimental conditions, the waterjet diffusion varies from the initial width of $10.00 \mathrm{~cm}$ to the impacting width about $40.00 \mathrm{~cm}$ (one-third of the depressurized chamber width) without coming into contact with solid walls; the non-atomized region in the flow direction and vertical direction takes up nearly two-thirds room of the depressurized chamber without affecting the atomized rain diffusion, and the walls on both sides along the flow direction can hinder the transverse diffusion of atomized rain to a certain extent; the horizontal diffusion of the waterjet is sufficient to produce a large amount of atomization, which can further result in splash atomized rain in the measurement area. As a consequence, the experimental design considers the verisimilitude of the physical model and the testability of the test object to maximize the simulation of the discharge environments in high-altitude and deep-canyon hydropower stations based on the existing decompression conditions. 
The first set of the experiment (Exp.1) was designed to measure the point rain amount in the horizontal plane by an electronic scale (accuracy of $0.01 \mathrm{~g}$ and range of $5 \mathrm{~kg}$ ), as detailed in Figure 2a,c. The point rain collecting device is located $450.00 \mathrm{~cm}$ long in the horizontal plane at the elevation of $-50.00 \mathrm{~cm}$, which includes two sections with upstream pile numbers of $984.00 \mathrm{~cm}$ and $1261.30 \mathrm{~cm}$. Ninety-one $(13 \times 7$ matrix $)$ and $28(14 \times 2$ matrix $)$ measurement points were placed separately in Regions I and II, respectively, for point rain collecting. The location of the center point on the rain point collector entrance face $(500 \mathrm{~mL}$ measurement cylinder with a diameter of $5.75 \mathrm{~cm})$ is defined as the measurement point coordinate. The rain collectors are placed at constant transects spacing $10.60 \mathrm{~cm}$ apart in the measurement plane, except for boundary points in the two measurement transition zones. To maintain the measurement points consistent, rain collectors were installed in the horizontal orifice plate $(D=86 \mathrm{~mm})$. The horizontal orifice plate was equipped with frame beams and bottom plates to prevent plane deformation and maintain rain collectors repeatable. To avoid ineffective atomized rain effects, a remote-controlled curtain ( $4.0 \mathrm{~m}$ in high and $1.20 \mathrm{~m}$ in wide) hung $50 \mathrm{~cm}$ upstream from Region I and a plastic cloth by adding pressure rods were used to cover the point collectors.

The second set of the experiment (Exp.2) was designed to measure the surface rain amount in the inclined plane, as detailed in Figure $2 \mathrm{a}, \mathrm{d}$. The surface rain was converged by a collecting panel and recorded by rain gauges at per minute. The rain surface collector is half of an inclined rectangular plate $\left(116.00 \mathrm{~cm}\right.$ wide $\times 97.50 \mathrm{~cm}$ high) that is inclined $18^{\circ}$ towards the downstream. The inclined rectangular plate is surrounded by a $3.00 \mathrm{~cm}$ high cofferdam, separated by a vertical separator with a thickness of $5 \mathrm{~mm}$ in the center, and arranged an overflow hole at the bottom corner. The rain gauge can self-record and is self-powered, with a measurement range of $0 \sim 4.0 \mathrm{~mm} / \mathrm{min}$ and a measurement accuracy of $\pm 0.2 \mathrm{~mm}$. The collecting precipitation flowed through the surface rain collector, a delivery pipe (free flow), an overflow diverter, three delivery pipes (free flow), and then into the rain gauges.

Figure 3 displays the schematic diagram with the water-regulating system in blue, the air-regulating system in red and the depressurized chamber in black. The water circulation system consists of three water pumps, nine water valves, and three electromagnetic flowmeters and one water level gauge, including three functional paths (replenish, circulate and drain water paths). The ambient pressure regulation system was designed to pump and replenish air. Five suction air pipes were connected to the top of the depressurized chamber, and two supplementary air pipes were connected to the atmosphere environment. In addition, a vacuum meter (the accuracy of $0.02 P_{0}$ and the range of $-1.0 P_{0} \sim 0 P_{0}$ ) and an absolute pressure sensor (the accuracy of $0.1 \%$ FS and the range of $0 \sim 10 \mathrm{~m}$ ) were arranged at the top of the depressurized chamber to record the ambient pressure.

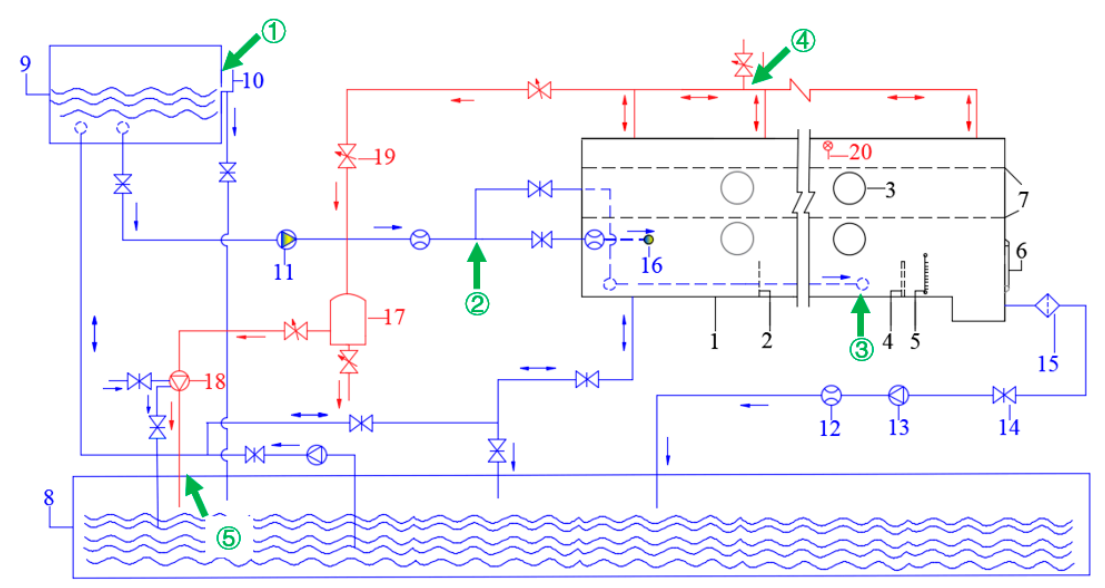

Figure 3. Schematic diagram of water-regulating and air-regulating systems. Notes: 1-depressurized chamber, 2-rectangular weir, 3-observation window, 4-rectifier grille, 5-water level gauge, 6-sealed door, 7-stiffening girder, 8-underground reservoir, 9-elevated water tank, 10-diversion weir tank, 11-jet pump, 12-electromagnetic flowmeter, 13-centrifugal pump, 14-water valve, 15-pipe strainer, 16-constricted nozzle, 17-sealed air tank, 18-vacuum pump, 19-air valve, 20-pressure gauge. 
The control and maintenance of the experimental system were very important, especially under unconventional operation conditions [41]. Some details were conducive to the stable adjustment of the experimental conditions (green arrows in Figure 3): two diversion positions were arranged on an elevated water tank (1) and behind a jet pump (2), and the branch flow was back into the depressurized chamber downstream (3)); suction and supplementary air pipes were connected with the same ventilation supervisor (4), and the air pipe of vacuum pump was extended to the underground reservoir to reduce air pollution (5)).

\subsection{Measurement Conditions and Data Statistics}

\subsubsection{Atomized Point Rain Measurement of Exp.1}

In Exp.1, the random splash experiment contained 20 conditions $\left(H_{i j}\right)$ with four inflow discharges $\left(Q_{i} /\left(\mathrm{m}^{3} / \mathrm{h}\right), i=1 \sim 4\right)$ and five low ambient pressures $\left(P_{j} / P_{0}, j=1 \sim 5\right)$, as shown in Table 1 . With the outlet surface area of the constricted nozzle $\left(30.00 \mathrm{~cm}^{2}\right)$, the average exit velocity $\left(V_{i} /(\mathrm{m} / \mathrm{s})\right)$ could be calculated. The effective collection time of each condition lasted $40 \mathrm{~min}$ and was duplicated three times, so the calculation time $(\Delta T)$ was $2 \mathrm{~h}$. The measurement principle was to weigh the increased precipitation in the point rain collector over an experimental period using an electronic scale. The effective measurement position and time of the point rain collector must be controlled.

Table 1. Operating conditions parameters of Exp.1.

\begin{tabular}{|c|c|c|c|c|c|c|c|}
\hline \multirow[b]{2}{*}{$\mathbf{H}_{i j}$} & \multirow{2}{*}{$\begin{array}{c}Q_{i} \\
\mathrm{~m}^{3} / \mathrm{h}\end{array}$} & \multirow{2}{*}{$\begin{array}{c}V_{i} \\
\mathrm{~m} / \mathrm{s}\end{array}$} & \multicolumn{5}{|c|}{$\boldsymbol{P}_{j} / \boldsymbol{P}_{0}$} \\
\hline & & & \multicolumn{5}{|c|}{$P_{0}=101.53 \mathrm{kPa}$} \\
\hline $\mathrm{H}_{1(1 \sim 5)}$ & 115.00 & 10.65 & 0.99 & 0.90 & 0.81 & 0.72 & 0.62 \\
\hline $\mathrm{H}_{2(1 \sim 5)}$ & 120.00 & 11.11 & 0.99 & 0.90 & 0.81 & 0.72 & 0.62 \\
\hline $\mathrm{H}_{3(1 \sim 5)}$ & 125.00 & 11.57 & 0.99 & 0.90 & 0.81 & 0.72 & 0.62 \\
\hline $\mathrm{H}_{4(1 \sim 5)}$ & 130.00 & 12.04 & 0.99 & 0.90 & 0.81 & 0.72 & 0.62 \\
\hline
\end{tabular}

In the horizontal plane, $P_{\left(x_{m}, y_{n}\right)}$ represents the mearing point, in which $m$ is the serial number ( $m=1 \sim 27$ ) of the point rain collectors along the $x$-axial direction (flow direction), $n$ is the serial number ( $n=1 \sim 7$ in Region I and $n=1 \sim 2$ in Region II) of the point rain collectors along the $y$-axial direction (transverse direction). Therefore, the increasing mass of the point rain collector $\left(M_{P\left(x_{m}, y_{n}\right)} / \mathrm{kg}\right)$ is expressed as the difference between the bottle mass before and after the experiment $(\mathrm{kg})$. With the inlet area of point rain collector $\left(A_{P}=2.60 \times 10^{-3} \mathrm{~m}^{2}\right)$, the average rain intensity of each point $\left.\left(R I_{p\left(x_{m}, y_{n}\right)}\right)(\mathrm{mm} / \mathrm{h})\right)$ can be determined by Equation (1). The average rain intensity $\left(\overline{R I}_{p\left(x_{m}, \bar{y}_{n}\right)} /(\mathrm{mm} / \mathrm{h})\right)$ of the transverse line along the $y$-axis in Regions I and II can be calculated by using Equations (2) and (3). Then, the rain distribution along the $x$-axis can be acquired.

$$
\begin{gathered}
R I_{p\left(x_{m}, y_{n}\right)}=M_{p\left(x_{m}, y_{n}\right)} /\left(\rho_{\mathrm{w}} \times A_{p} \times \Delta T \times 10^{3}\right), \\
\overline{R I}_{p\left(x_{m}, \bar{y}_{n}\right)}=\sum_{n=1}^{7}\left(M_{p\left(x_{m}, y_{n}\right)} /\left(\rho_{w} \times A_{p} \times \Delta T \times 10^{3}\right) / n,\right. \\
\overline{R I}_{p\left(x_{m}, \bar{y}_{n}\right)}=\sum_{n=1}^{2}\left(M_{p\left(x_{m}, y_{n}\right)} /\left(\rho_{w} \times A_{p} \times \Delta T \times 10^{3}\right) / n,\right.
\end{gathered}
$$

where $\rho_{w}=1000 \mathrm{~kg} / \mathrm{m}^{3}$.

\subsubsection{Atomized Surface Rain Measurement of Exp.2}

In Exp.2, the random splash experiment contained 25 conditions $\left(\mathrm{I}_{i j}\right)$ of Exp.2 with five inflow discharges $\left(Q_{i} /\left(\mathrm{m}^{3} / \mathrm{h}\right), i=1 \sim 5\right)$ and five low ambient pressures $\left(P_{j}, j=1 \sim 5\right)$, as shown in Table 2 . 
With the outlet area of the constricted nozzle $\left(30.00 \mathrm{~cm}^{2}\right)$, the average exit velocity $\left(V_{i} /(\mathrm{m} / \mathrm{s})\right)$ could be obtained. The effective collection time of each condition in Exp.2 was continued for 10 min and duplicated three times. The surface rain was recorded per minute using rain gauges, so the control of the confluence rain amount in the test range of rain gauge effectively was important for experimental success.

Table 2. Operating conditions parameters of Exp.2.

\begin{tabular}{cccccccc}
\hline & $Q_{i}$ & $V_{i}$ & \multicolumn{5}{c}{$\boldsymbol{P}_{j} / \boldsymbol{P}_{0}$} \\
$\mathrm{I}_{i j}$ & $\mathbf{m}^{\mathbf{3}} / \mathbf{h}$ & $\mathbf{m} / \mathbf{s}$ & & \multicolumn{3}{c}{$\boldsymbol{P}_{\mathbf{0}}=\mathbf{1 0 1 . 5 3} \mathbf{~ k P a}$} \\
& 115.39 & 10.68 & 0.99 & 0.90 & 0.81 & 0.72 & 0.62 \\
$\mathrm{I}_{1(1 \sim 5)}$ & 119.97 & 11.11 & 0.99 & 0.90 & 0.81 & 0.72 & 0.62 \\
$\mathrm{I}_{2(1 \sim 5)}$ & 124.74 & 11.55 & 0.99 & 0.90 & 0.81 & 0.72 & 0.62 \\
$\mathrm{I}_{3(1 \sim 5)}$ & 126.00 & 11.67 & 0.99 & 0.90 & 0.81 & 0.72 & 0.62 \\
$\mathrm{I}_{4(1 \sim 5)}$ & 127.68 & 11.82 & 0.99 & 0.90 & 0.81 & 0.72 & 0.62 \\
$\mathrm{I}_{5(1 \sim 5)}$ & & & & & & & \\
\hline
\end{tabular}

In the inclined plane, synchronizing the rain gauge time with a stopwatch was helpful to identify the effective working period before the experimental processing; the converged flow was regulated by three water valves near the overflow diverter. During the experimental processing, the effective test start time was set $10 \mathrm{~min}$ later than the debugging completion time to ensure stability; the water level of the airtight cylinder was below the bottom of the rain gauge. The instantaneous rain intensity $\left(R I_{S} /(\mathrm{mm} / \mathrm{h})\right)$, average rain amount $\left(R A_{S} /(\mathrm{L} / \mathrm{h})\right)$ and atomized source ratio $\left(R_{S} /\left(10^{-3} \%\right)\right)$ in the inclined plane can be given by Equations (4)-(6).

$$
\begin{gathered}
R I_{S}=\left(60 \times A_{L} \times \sum_{L=1}^{3} I_{L K}\right) /\left(A_{S} / 2\right), \\
R A_{S}=A_{L} \times \sum_{L=1}^{3} I_{L K} \times\left(T_{K} \times 2\right), \\
R_{S}=\left(R A_{S} \times 100\right) / Q_{i}
\end{gathered}
$$

where $A_{L}$ is the area of the single-electrical recording gauge $\left(3.14 \times 10^{-2} \mathrm{~m}^{2}\right), L$ is the serial number of the electrical recording gauges, $I_{L K}$ is the rain intensity recorded by single-electrical recording gauge $(\mathrm{mm} / \mathrm{min}), T_{K}$ is the calculation time $(30 \mathrm{~min})$, the measurement surface is $\left(A_{S} / 2\right), A_{\mathrm{S}}$ is $1.13 \mathrm{~m}^{2}$, and $Q_{i}$ is the inflow discharge, $\mathrm{m}^{3} / \mathrm{h}$.

\section{Results and Discussions}

\subsection{Horizontal Plane Distribution of Atomized Rain}

Atomized rain is commonly characterized by the rain intensity, which is used to classify the atomized zone. The average rain intensity of each point in Regions I and II was calculated according to Equation (1). Figure 4 depicts the atomized rain distribution described by cloud atlas with 10 equidistant color levels. In all cases, the rain intensity ranges are separately within $0 \sim 5,0 \sim 10,0 \sim 20$, and $0 \sim 60 \mathrm{~mm} / \mathrm{h}$ under inflow discharge conditions with $115,120,125$, and $130 \mathrm{~m}^{3} / \mathrm{h}$. 


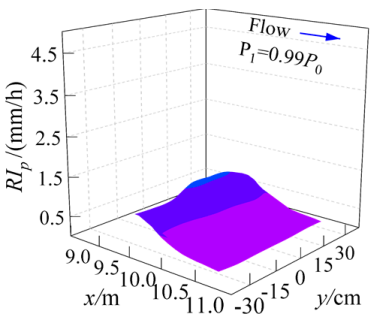

(a1) Case $\mathrm{H}_{11}$

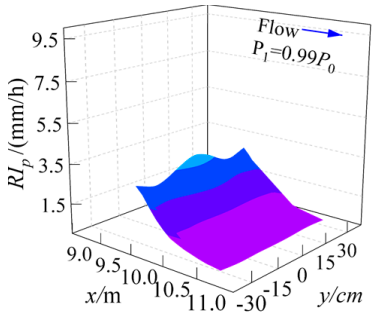

(b1) Case $\mathrm{H}_{21}$

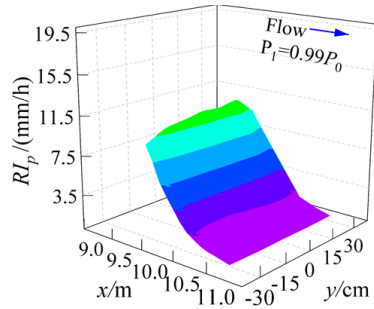

(c1) Case $\mathrm{H}_{31}$

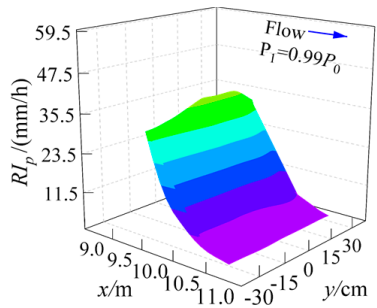

(d1) Case $\mathrm{H}_{41}$

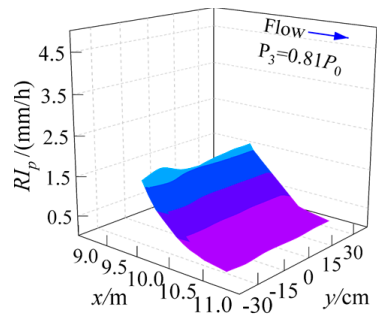

(a2) Case $\mathrm{H}_{13}$

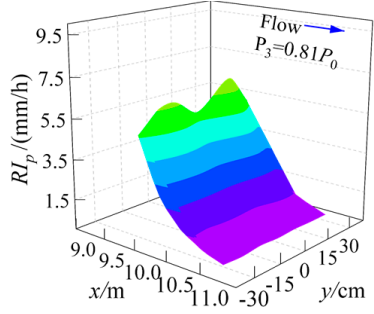

(b) Case $\mathrm{H}_{23}$

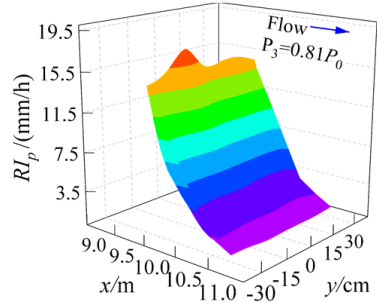

(c2) Case $\mathrm{H}_{33}$

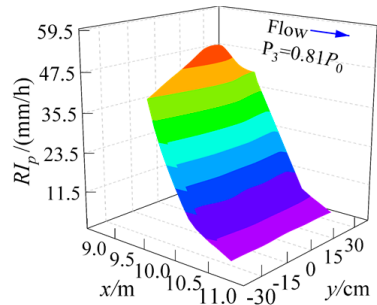

(d2) Case $\mathrm{H}_{43}$

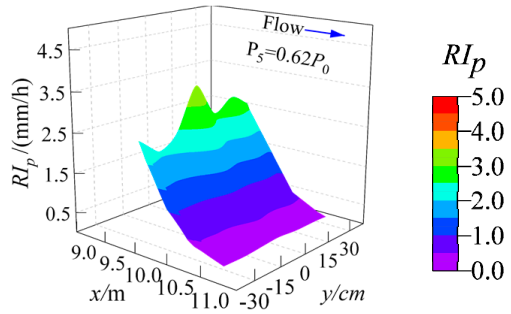

(a3) Case $\mathrm{H}_{15}$

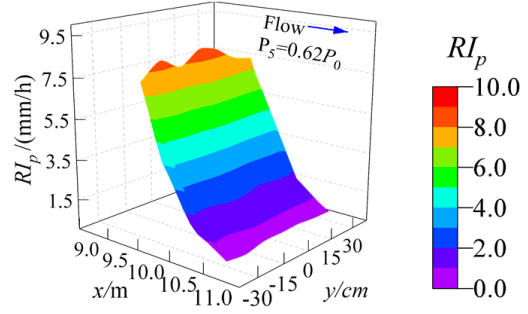

(b) Case $\mathrm{H}_{25}$

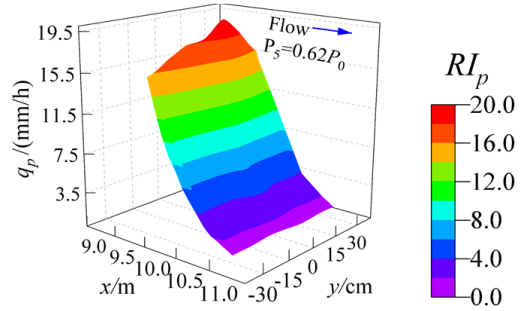

(c3) Case $\mathrm{H}_{35}$

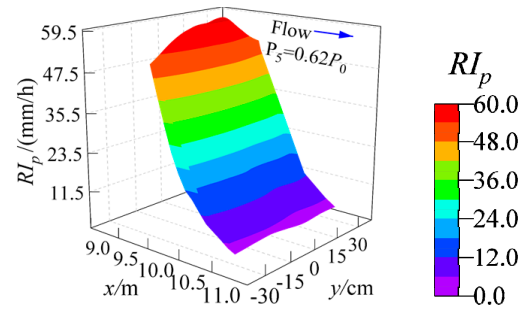

(d) Case $\mathrm{H}_{45}$

Figure 4. Rain intensity distribution of each point in Region I affected by low ambient pressure. (a) $Q$ $=115.00 \mathrm{~m}^{3} / \mathrm{h}$ and $V=10.65 \mathrm{~m} / \mathrm{s} ;(\mathbf{b}) Q=120 \mathrm{~m}^{3} / \mathrm{h}$ and $V=11.11 \mathrm{~m} / \mathrm{s} ;(\mathbf{c}) Q=125.00 \mathrm{~m}^{3} / \mathrm{h}$ and $V=$ $11.57 \mathrm{~m} / \mathrm{s} ;(\mathbf{d}) Q=130.00 \mathrm{~m}^{3} / \mathrm{h}$ and $V=12.04 \mathrm{~m} / \mathrm{s}$.

It can be seen from Figure 4 that the point rain intensity in the horizontal plane increases under constant inflow discharge conditions with the decreasing of ambient pressure, which causes an increase in the atomized zone and attenuation gradient in the flow direction along the $x$-axis; the rain intensity of majority measurement points in the horizontal plane increases with increasing inflow discharge under conditions with certain low ambient pressure, which is consistent with the trend of the ambient pressure effect. Comparing the enhanced effects on atomized rain induced by the lower ambient pressure and higher inflow discharge, although the increment of atomized rain intensity range due to the decrease in ambient pressure by about $0.40 P_{0}$ is smaller than that due to the increase in inflow discharge by $5 \mathrm{~m}^{3} / \mathrm{h}$, the effect of low pressure is also very obvious, directly leading to the extension of the local protection area to the downstream. 
It also can be seen from Figure 4 that the two-dimensional distribution of atomized rain under low ambient pressure shares the same trend with that under normal pressure, in which the transverse gradient is closely symmetrical with a small gradient and the flow gradient decreases with the first steep change and then slows. Additionally, the reason for the transverse distributed rule is that the transverse diffusion of atomized water-droplets is nearly equal to the depressurized chamber width in a short time, as the measurement zone width is approximately twice the entry-water width of the waterjet and two-thirds the width of the water cushion zone. Meanwhile, the reason for the difference in flow distribution is due to the diversity movement of atomized water-droplets generated by the splashing of the waterjet front edge. The movement difference of atomized water-droplets is a result of the emission conditions (velocity, angle, diameter, etc.) and diffusion environment (natural wind, waterjet wind, three-dimensional terrain, ambient pressure, etc.) [15,18,19].

To further analyze the influence of low ambient pressure on rain intensity line range along the flow direction of the horizontal plane, the average rain intensity of the transverse line was calculated according to Equations (2) and (3). According to the partition standard of atomized rain, the atomized rain zone can be divided into four types by using rain intensity lines at 2, 10 and $40 \mathrm{~mm} / \mathrm{h}$; namely, a light fog and vapor area, a mist and rainfall area, a heavy fog and rainstorm area and a waterjet spallation and splash area. Therefore, the distance of rain intensity lines $(40,10,2 \mathrm{~mm} / \mathrm{h})$ of the horizontal plane from the constricted nozzle outlet affected by low ambient pressure can be calculated by fitting calculation, as shown in Figure 5a,b.

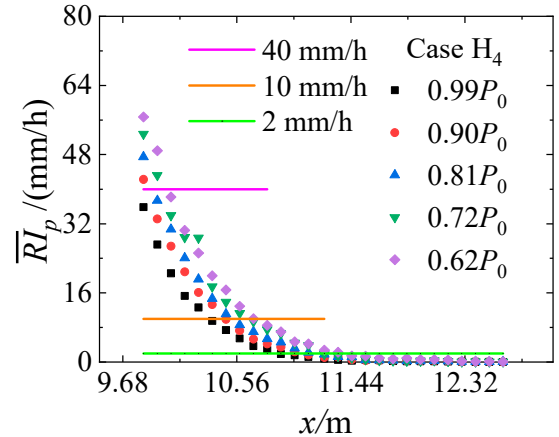

(a)

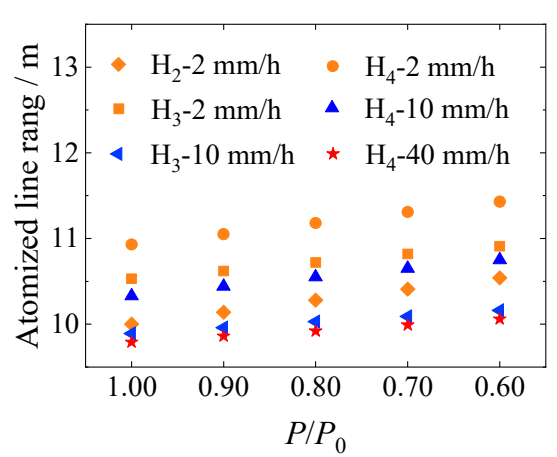

(b)

Figure 5. Range of characteristic rain intensity lines affected by low ambient pressure. (a) Fitting calculation of case $\mathrm{H} 4$; (b) Atomized line range of Case $\mathrm{H}_{2} \sim \mathrm{H}_{4}$; Case $\mathrm{H}_{2}$ with $Q=120.00 \mathrm{~m}^{3} / \mathrm{h}$ and $V=11.11 \mathrm{~m} / \mathrm{s}$, Case $\mathrm{H}_{3}$ with $Q=125.00 \mathrm{~m}^{3} / \mathrm{h}$ and $V=11.57 \mathrm{~m} / \mathrm{s}$, Case $\mathrm{H}_{4}$ with $Q=130.00 \mathrm{~m}^{3} / \mathrm{h}$ and $V=12.04 \mathrm{~m} / \mathrm{s}$.

It can be found in Figure 5 a that the distributed trend along the flow direction can be well-matched with a composite exponential formula of $\exp \left(a+b x+c x^{2}\right)$ under constant test conditions. Therefore, the measuring points in this atomized rain area can be simplified appropriately according to the function relation in a similar experiment, in which it is advisable to arrange $3 \sim 5$ measuring points in different atomized rain areas.

It can be found in Figure $5 \mathrm{~b}$ that when the ambient pressure drops by $0.10 P_{0}$, the range of the characteristic rain intensity line at $2 \mathrm{~mm} / \mathrm{h}$ experiences an increase of $0.10 \sim 0.14 \mathrm{~m}$ and that of 10 and $40 \mathrm{~mm} / \mathrm{h}$ separately increase by $0.07 \mathrm{~m} \sim 0.10 \mathrm{~m}$ and $0.07 \mathrm{~m}$, respectively, which is in accordance with linear growth rates within the ranges of $0.92 \sim 1.37,0.68 \sim 1.01$ and $0.69\left(\% /\left(0.10 P_{0}\right)\right)$, respectively, under experimental inflow discharges. Under the constant inflow discharge, the effect degrees of low ambient pressure on the mist and rainfall area (rain intensity $\geq 2 \mathrm{~mm} / \mathrm{h}$ ), the heavy fog and rainstorm area (rain intensity $\geq 10 \mathrm{~mm} / \mathrm{h}$ ), and the waterjet spallation and splash area (rain intensity $\geq$ $40 \mathrm{~mm} / \mathrm{h}$ ) are decreased in turn. Surprisingly, in the mist and rainfall area, the rain intensity tends to coincide as the $x$-axis increases, regardless of ambient pressure. Therefore, it can be inferred that the atomized rainstorm area (rain intensity $\geq 10 \mathrm{~mm} / \mathrm{h}$ ) of high-altitude hydro-junction possibly appears in unprotected areas without considering low ambient pressure correction. 


\subsection{Inclined Plane Distribution of Atomized Rain}

In the atomized protection of actual projects, the local protection also plays an equally important role as the whole protection. For instance, the tunnel portal and powerhouse all require a drainage system based on the assessment of surface confluent rain. Therefore, the instantaneous rain intensity of the inclined plane is calculated according to Equation (4). Figure 6 displays the instantaneous rain intensity of the inclined plane affected by low ambient pressure with five inflow discharge conditions, which is distributed on a radar map including 30 circumferential time nodes and six radial rain intensity contours that increase from inner circle to outer circle with equal gradient. The rain intensity intervals are within $0 \sim 3,2 \sim 7,4 \sim 14,12 \sim 27$, and 16 36 mm/h, which separately correspond with the cases of $\mathrm{I}_{1(1 \sim 5)}, \mathrm{I}_{2(1 \sim 5)}, \mathrm{I}_{3(1 \sim 5)}, \mathrm{I}_{4(1 \sim 5)}$ and $\mathrm{I}_{5(1 \sim 5)}$ (Figure 6a-e).

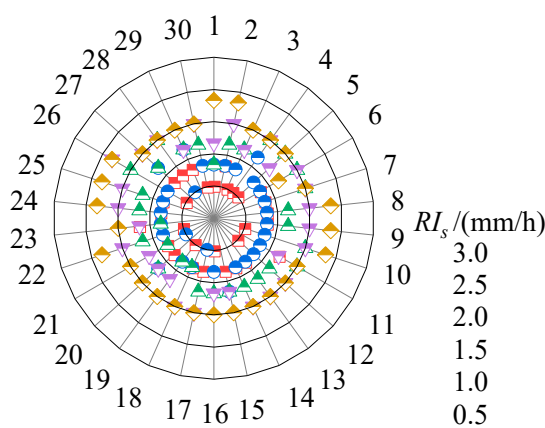

(a) Cases $\mathrm{I}_{1(1 \sim 5)}$

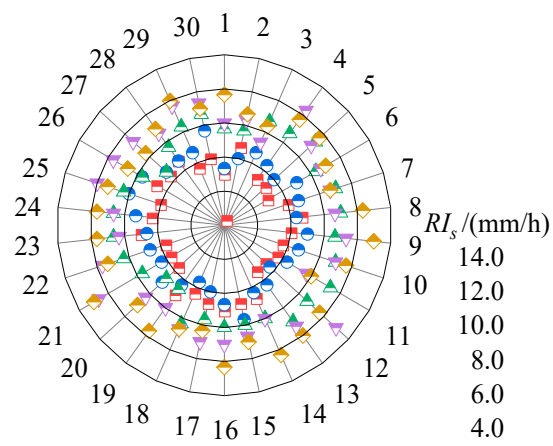

(c) Cases $I_{3(1 \sim 5)}$

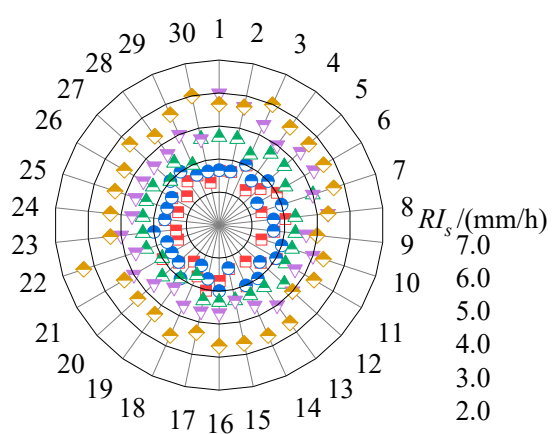

(b) Cases I2(1 5)

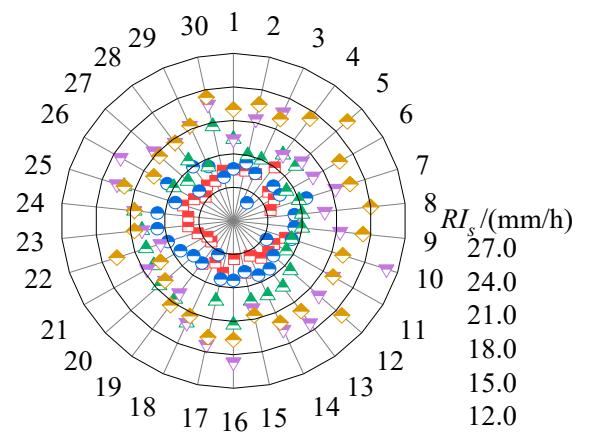

(d) Cases $\mathrm{I}_{4(1 \sim 5)}$

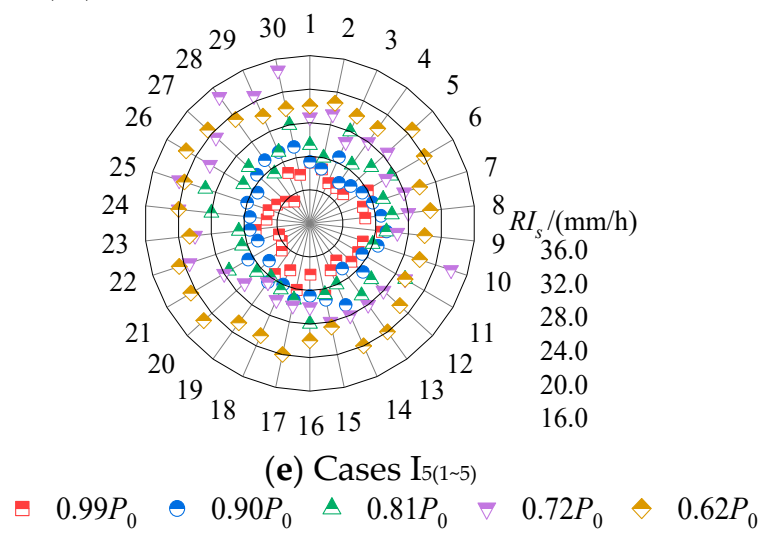

Figure 6. Instantaneous rain intensity of inclined plane affected by low ambient pressure (time notes along circumferential direction). (a) $Q=115.39 \mathrm{~m}^{3} / \mathrm{h}$ and $V=10.68 \mathrm{~m} / \mathrm{s}$; (b) $Q=119.97 \mathrm{~m}^{3} / \mathrm{h}$ and $V$ $=11.11 \mathrm{~m} / \mathrm{s} ;$ (c) $Q=124.74 \mathrm{~m}^{3} / \mathrm{h}$ and $V=11.55 \mathrm{~m} / \mathrm{s} ;(\mathbf{d}) Q=126.00 \mathrm{~m}^{3} / \mathrm{h}$ and $V=11.67 \mathrm{~m} / \mathrm{s} ;(\mathbf{e}) Q=$ $127.68 \mathrm{~m}^{3} / \mathrm{h}$ and $V=11.82 \mathrm{~m} / \mathrm{s}$. 
As illustrated in Figure 6, the instantaneous rain intensity of the inclined plane expands outward radially as the ambient pressure decreases with constant inflow discharge, which indicates that the instantaneous rain intensity can be affected by the ambient pressure reduction. Also, the decrease in ambient pressure increases the mean value of the instantaneous rain intensity and the growth rate increases as the inflow discharge increases. This results from the integrated impacts, such as the waterjet characteristics, which are related to the atomized line source amount and the air resistance, directly affecting the atomized water-droplets diffusion. Meanwhile, under certain low ambient pressure conditions, increasing the inflow discharge causes the mean value and fluctuation interval to increase. This is mostly because the principal component of the atomized droplet spectrum gradually changes from small diffused droplets to large splash droplets with increasing inflow discharge, which increases the base weight and randomness of the confluent rain.

To further analyze the influence of low ambient pressure on average rain amount characteristics in the inclined plane, the surface average rain amount is calculated according to Equation (5), as shown in Figure 7. Then, the atomized rain increment $\left(G_{P}\right)$ and increased percentage $\left(G_{P}\right)$ are calculated when the ambient pressure dropped by $0.10 P_{0}$, and then the required inflow discharge increment $\left(G_{Q}\right)$ and increased percentage $\left(\mathrm{GP}_{\mathrm{Q}}\right)$ for the same atomized rain increment under stranded pressure $P_{0}$ $(101.53 \mathrm{kPa})$ are calculated averagely, as indicated in Table 3.

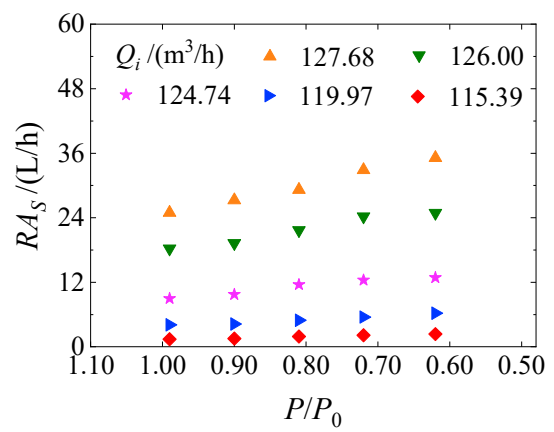

(a)

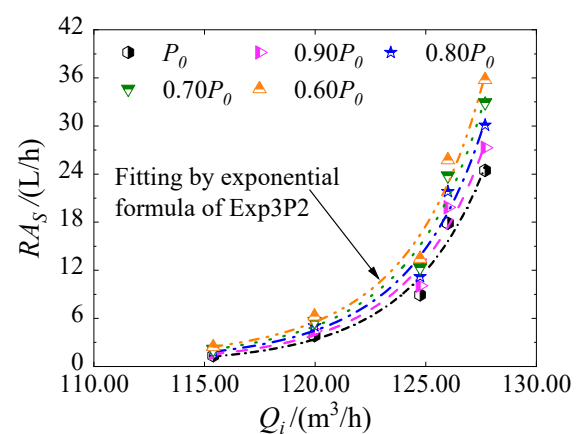

(b)

Figure 7. Average rain amount characteristics. (a) Affected by low ambient pressure; (b) Affected by inflow discharge.

Table 3. Equivalent increase of average rain amount by decreasing ambient pressure and increasing inflow discharge.

\begin{tabular}{ccccc}
\hline$Q_{i}$ & $\mathrm{G}_{\boldsymbol{P}}$ & $\mathrm{GP}_{\boldsymbol{P}}$ & $\mathrm{G}_{Q}$ & $\mathrm{GP}_{Q}$ \\
\hline $\mathbf{m}^{\mathbf{3}} \mathbf{h}$ & $\mathbf{L} / \mathbf{h}$ & $\mathbf{\%}$ & $\mathbf{m}^{\mathbf{3}} / \mathbf{h}$ & $\mathbf{\%}$ \\
\hline 115.39 & 0.28 & 20.48 & 0.62 & 0.53 \\
119.97 & 0.61 & 15.89 & 0.53 & 0.44 \\
124.74 & 1.13 & 12.65 & 0.45 & 0.36 \\
126.00 & 1.98 & 11.06 & 0.41 & 0.33 \\
127.68 & 2.83 & 11.56 & 0.43 & 0.34 \\
\hline
\end{tabular}

It can be found in Figure 7a and Table 3 that the links between the average rain amount growth and the ambient pressure reduction obey a linear relationship under constant inflow discharge in the inclined plane. When the ambient pressure is reduced by $0.10 P_{0}$, the linear growth amounts under inflow discharge conditions of $115.39,119.97,124.74,126.00$ and $127.68 \mathrm{~m}^{3} / \mathrm{h}$ are $0.28,0.61,1.13,1.98$ and $2.83 \mathrm{~L} / \mathrm{h}$, respectively, with growth rates $20.48 \%, 15.89 \%, 12.65 \%, 11.06 \%$ and $11.56 \%$. Meanwhile, a higher inflow discharge can lead to a stronger enhancement effect of low ambient pressure on the average rain amount with the growth rate from sharp to stable. In addition, the atomized source ratio is within $\left((0 \sim 30) \times 10^{-3}\right) \%$ according to Equation (6), which matches the same trend of average rain amount affected by low ambient pressure. 
It can be found in Figure $7 \mathrm{~b}$ and Table 3 that, under constant low ambient pressure conditions, the average rain amount increase results from the increase in inflow discharge. Under conditions with experimental inflow discharges, the growth of the average rain amount can be quantified by increasing the inflow discharge of $0.41 \sim 0.62 \mathrm{~m}^{3} / \mathrm{h}$ as the ambient pressure drops by $0.10 P_{0}$, which is equal to an increase of $0.33 \% \sim 0.53 \%$ relative to the standard inflow discharge. The higher the inflow discharge is, the smaller the compensation inflow discharge is, because the average rain amount increases with a composite exponential formula of $\exp \left(a+b Q_{i}+c Q_{i}{ }^{2}\right)$ as the inflow discharge increases. Therefore, the average rain amount atomized in the local area is relatively sensitive, regardless of the ambient pressure decreases and the inflow discharge increases.

\subsection{Analysis of Depressurized Effects}

In random splash theory [14-16], the atomized process can be described as a semi-empirical and semi-theoretical model that considers the impinging outer edges of waterjets as atomized line sources and splash droplets as independently moving spheres. Therefore, the movements of experimental waterjets and atomized water-droplets are taken into account in this section.

Figures 8 and 9 display the waterjet diffusion in air and the downstream flow pattern in the water cushion. In Figure 8, the horizontal diffusion of the waterjet is obvious due to a high exit velocity at a magnitude of $10 \mathrm{~m} / \mathrm{s}$. Compared with the horizontal images in Figures 8 and 9, the low ambient pressure with the same inflow discharge can narrow the waterjet transverse diffusion width and lessen the side-spallation under conditions with different ambient pressures and the same inflow discharge, but this parameter has less effect on the water-collision location and the downstream flow pattern in the water cushion. As stated in the studies of [31,42,43], waterjet properties can vary with aeration concentration. Zhang et al. [31] found that the upper boundaries of aerated waterjets become shorter as the aeration concentration of circular waterjets decreases and that the spallation water-droplet velocities tend to be higher. Deng et al. [42] stated that scour can become stronger when induced by rectangular submerged waterjets under experimental conditions with a lower aeration concentration and the same inflow velocity. Dong et al. [43] discovered that, regarding the dynamic pressure on the bottom of a water cushion generated by a two-dimensional submerged waterjet, the lower the aeration concentration of the waterjet is, the higher the averaged pressure is, and the lower the fluctuation pressure is. Therefore, it is speculated that the aeration concentration of the waterjet outer boundary can decrease in a low ambient pressure environment, which can increase the number of atomized line sources due to the increase in the water-entry velocity of impacting waterjet.

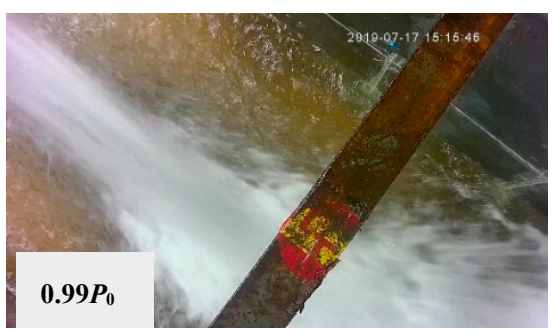

(a1) Case $\mathrm{H}_{11}$

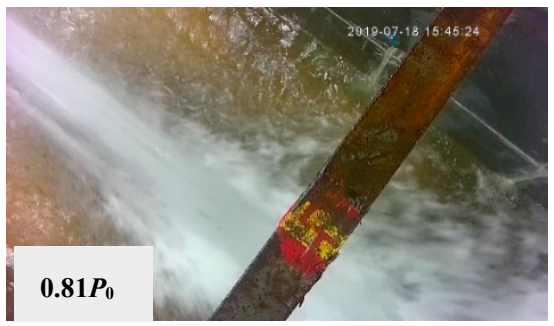

(a2) Case $\mathrm{H}_{13}$

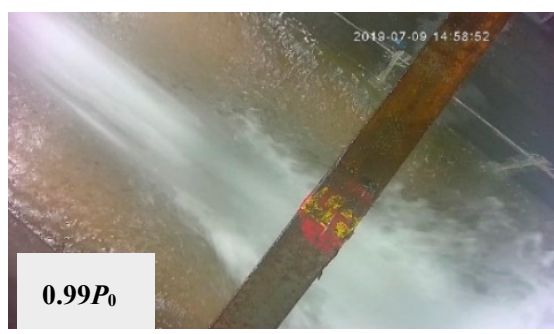

(b1) Case $\mathrm{H}_{31}$

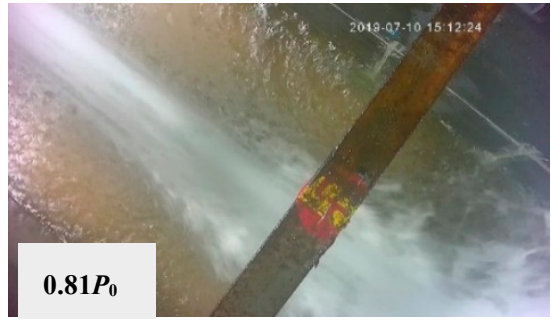

(b) Case $\mathrm{H}_{33}$

Figure 8. Cont. 


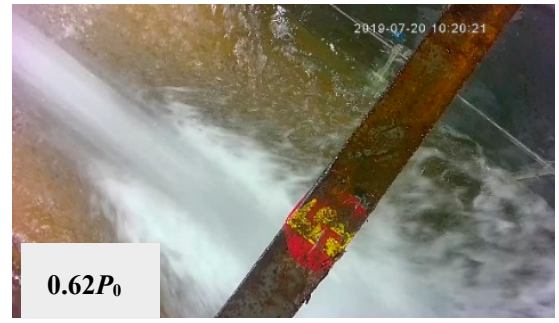

(a) Case $\mathrm{H}_{15}$

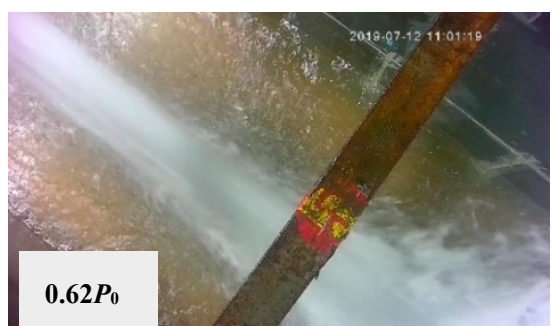

(b3) Case $\mathrm{H}_{35}$

Figure 8. Waterjet aerial diffusion affected by low ambient pressure. (a) $Q=115.00 \mathrm{~m}^{3} / \mathrm{h}$ and $V=$ $10.65 \mathrm{~m} / \mathrm{s} ;$ (b) $Q=125.00 \mathrm{~m}^{3} / \mathrm{h}$ and $V=11.57 \mathrm{~m} / \mathrm{s}$.

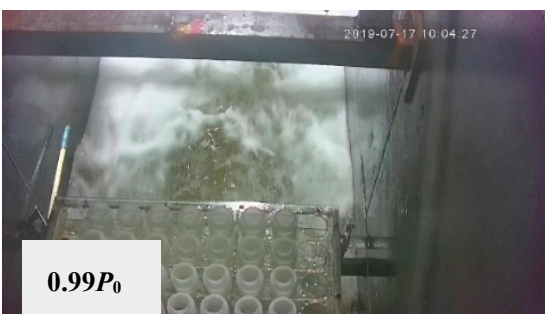

(a1) Case $\mathrm{H}_{11}$

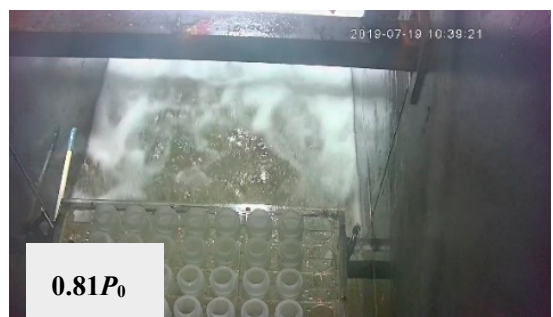

(a2) Case $\mathrm{H}_{13}$

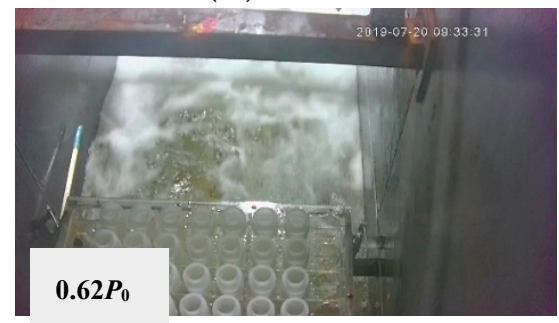

(a) Case $\mathrm{H}_{15}$

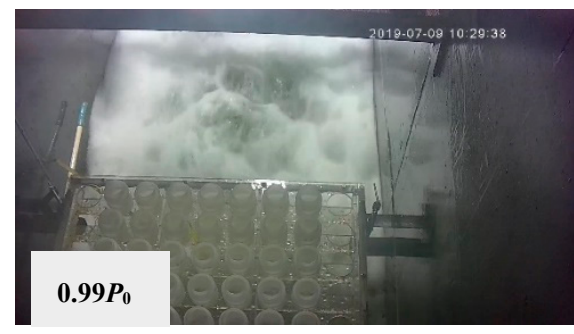

(b) Case $\mathrm{H}_{31}$

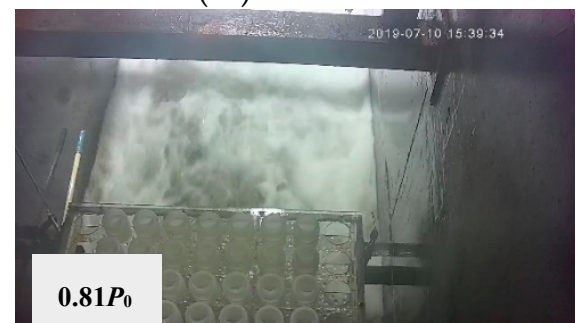

(b) Case $\mathrm{H}_{33}$

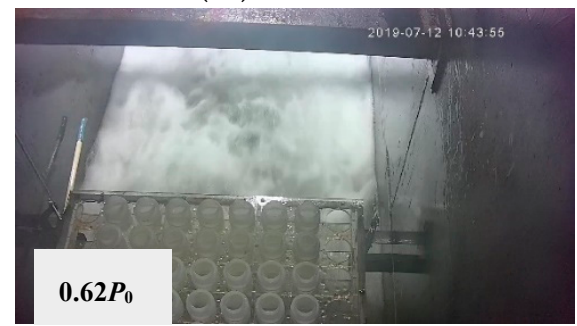

(b) Case $\mathrm{H}_{35}$

Figure 9. Downstream flow patterns in water cushion affected by low ambient pressure. (a) $Q=$ $115.00 \mathrm{~m}^{3} / \mathrm{h}$ and $V=10.65 \mathrm{~m} / \mathrm{s} ;(\mathbf{b}) Q=125.00 \mathrm{~m}^{3} / \mathrm{h}$ and $V=11.57 \mathrm{~m} / \mathrm{s}$.

Meanwhile, the atomized water-droplet velocity can be described by Equation (7).

$$
\frac{d v_{i}^{\prime}}{d t}=-c_{f}\left|v^{\prime}-v_{f}^{\prime}\right| \times \frac{3}{4 D} \frac{\rho_{\mathrm{a}}}{\rho_{\mathrm{w}}}\left(v_{i}^{\prime}-v_{f i}^{\prime}\right)+\frac{\rho_{a}-\rho_{w}}{\rho_{w}} g_{i} \quad(i=1,2,3),
$$

where, $v^{\prime}$ and $v_{f}^{\prime}$ are the atomized water-droplet velocity and wind velocity $(\mathrm{m} / \mathrm{s})$, respectively; $v_{i}^{\prime}$ and $v_{f i}^{\prime}$ are the components of the atomized water-droplet velocity and wind velocity (m/s), respectively; $g_{i}$ is the gravitational acceleration, $\left(\mathrm{m} / \mathrm{s}^{2}\right) ; i$ represents the axis in the cartesian coordinate system $(\mathrm{m} / \mathrm{s}) ;$ $\rho_{\mathrm{w}}$ and $\rho_{\mathrm{a}}$ are the water and air density $\left(\mathrm{kg} / \mathrm{m}^{3}\right)$, respectively; $D$ is the average diameter of atomized water-droplet, $0.003 \mathrm{~m} \sim 0.005 \mathrm{~m}, c_{f}$ is the air resistance coefficient of atomized droplet, $c_{f}$ depends on the relative Reynolds number $\operatorname{Re}_{d}=\left(\frac{\left|v^{\prime}-v_{f}^{\prime}\right| D}{v_{\mathrm{a}}}\right)$, and $v_{\mathrm{a}}$ is the dynamic viscosity coefficient of air. 
As indicated in Equation (7), the atomized water-droplet velocity is dependent on the initial injection and environmental conditions and can be solved by the Fourth-Order Runge-Kutta method. Both the atomized water-droplet velocity and wind velocity are generalized by the water-entry velocity of impacting waterjet [14]. The air resistance coefficient is close to 0.44 as the exit velocity of the experimental waterjet is in the order of $10 \mathrm{~m} / \mathrm{s}$ in this experiment [18]. Although the decrease in air density can bring on the decrease in air resistance and the increase of buoyancy force, the decrease in air resistance has more impact than the increase in the buoyancy force [30]. Therefore, it can be further indicated that the decrease in air density can also make a direct contribution to the enhancement of downstream atomized rain.

Both lower ambient pressure and higher inflow discharge can enhance downstream atomized rain, but with different mechanics. Compared with the vertical images in Figures 8 and 9, as the inflow discharge increases with the same ambient pressure, the water-collision locations obviously move downstream, and the milky white zones of the water cushion surface expand. Therefore, the main contribution of the enhancement in downstream atomized rain due to the increase in inflow discharge is the downstream movement of the water-collision location and the enlargement of the atomized line sources due to higher impacting waterjet velocities. Therefore, an in-depth study on the high-velocity diffusion mechanism of aerated waterjets and atomized water-droplets in low ambient pressure environments needs to be carried out.

\section{Conclusions}

The links between downstream atomized rain and low ambient pressure are investigated by the random splash experiment in the depressurized chamber, in which the waterjet exit velocity is in the order of a $10 \mathrm{~m} / \mathrm{s}$ release and the low ambient pressure is reduced from approximately $1.00 P_{0}$ to $0.60 P_{0}$. The main conclusions are listed below:

(1) Under constant low ambient pressure conditions, both the point rain intensity and surface rain amount increase with increasing inflow discharge; the average rain intensity in the horizontal plane is symmetrical and similar in the transverse direction and decreases along the flow direction; both the decreasing trend of average rain intensity along the releasing centerline $(x)$ and the increasing trend of average rain amount with an enlarged outflow flux $\left(Q_{i}\right)$ can be described by the exponential formula of $\exp \left(a+b x+c x^{2}\right)$ and $\exp \left(a+b Q_{i}+c Q_{i}^{2}\right)$.

(2) As the ambient pressure decreases, the point rain intensity increases, and the rain intensity lines extend linearly downstream in the horizontal plane. The downstream expansion distances of rain lines at 2,10 and $40 \mathrm{~mm} / \mathrm{h}$ are within $0.10 \sim 0.14 \mathrm{~m} / 0.10 P_{0}, 0.07 \sim 0.10 \mathrm{~m} / 0.10 P_{0}$, and $0.07 \mathrm{~m} / 0.10 P_{0}$, respectively, and the expansion rates are within $0.92 \% \sim 1.37 \% / 0.10 P_{0}, 0.68 \% \sim 1.01 \% / 0.10 P_{0}$ and $0.69 \% / 0.10 P_{0}$, respectively, separately corresponding to experimental conditions with inflow discharges of 120.00 $\mathrm{m}^{3} / \mathrm{h}, 125.00 \mathrm{~m}^{3} / \mathrm{h}$, and $130.00 \mathrm{~m}^{3} / \mathrm{h}$. So the atomized rainstorm area in high-altitude hydro-junction need be expanded by considering low ambient pressure correction.

(3) As the ambient pressure decreases, the instantaneous and mean value of surface rain intensity increase, along with the expansion of the fluctuation interval, which results in a linear increase in the average rain amount and mean amount ratio (within $\left((0 \sim 30) \times 10^{-3}\right) \%$ ) in the inclined plane. The average rain amount under low ambient pressure conditions is larger, within $0.28 \sim 2.83 \mathrm{~L} / \mathrm{h} / 0.10 P_{0}$, and the percentage of average rain amount is larger, within $11.06 \% \sim 20.48 \% / 0.10 P_{0}$. Additionally, the equivalent increase in average rain amount affected by low ambient pressure can be quantified by adjusting the inflow discharge with nonlinear variation in experimental conditions.

(4) The transverse diffusion of an aerial waterjet decreases under low ambient pressure conditions, while the waterjet impact position, as well as the downstream flow pattern in the water cushion, remain almost invariant. Further analysis pointed out that the reduction in the waterjet aeration and air density can directly enhance the downstream atomized rain under low ambient pressure conditions.

The low ambient pressure enhancement effect on downstream atomized rain has been confirmed from the experimental results, which means that multi-scale predictive methods and multi-form 
protective modes need to be explored. Additionally, the quantitative study on the variation of the intensity and range of atomized rain in low ambient pressure conditions can accurately improve the atomized protection standard of prototypical discharge project in the high-altitude area. In the future, it is urgent to carry out long-term systematic research with multi-objective optimization requirements on flood discharge atomization of high-altitude hydropower stations integrated in the areas of quality and cost control with eco-friendly. Our further studies will focus on mechanism analysis and numerical prediction so as to provide a theoretical foundation for flood discharge atomization prediction of high dam projects in high altitude areas.

Author Contributions: Conceptualization, J.L.; methodology, J.L. and D.L. (Dan Liu); formal analysis, F.L. and D.L. (Dan Liu); data curation, D.L. (Dan Liu); writing-original draft preparation, D.L. (Dan Liu) and J.S.; writing-review and editing, D.L. (Dongming Liu) and B.M. All authors have read and agreed to the published version of the manuscript.

Funding: This research was funded by National Key R\&D Program of China, grant number 2016YFC0401904; National Natural Science Foundation of China, grant number U1765202; National Natural Science Foundation of China, grant number 51779167; Scientific and Technological Project of China Huaneng Group, Grant No. HNKJ16-H12; 2016 Free Exploration Project of Academician Hongqi Ma in Yunnan Province, Grant No. 2016HA012; Science Fund for Innovative Research Groups of the National Natural Science Foundation of China, grant No. 51621092.

Acknowledgments: The authors would like to express their sincere gratitude to all of those who have offered selfness help during the course of this research.

Conflicts of Interest: The authors declare no conflict of interest.

\section{References}

1. Wagner, B.; Hauer, C.; Habersack, H. Current hydropower developments in Europe. Curr. Opin. Environ. Sustain. 2019, 37, 41-49. [CrossRef]

2. Tang, S.; Chen, J.; Sun, P.; Li, Y.; Yu, P.; Chen, E. Current and future hydropower development in Southeast Asia countries (Malaysia, Indonesia, Thailand and Myanmar). Energy Policy 2019, 129, 239-249. [CrossRef]

3. Li, X.Z.; Chen, Z.J.; Fan, X.C.; Cheng, Z.J. Hydropower development situation and prospects in China. Renew. Sustain. Energy Rev. 2018, 82, 232-239. [CrossRef]

4. Lempérière, F. Dams and Floods. Engineering 2017, 3, 144-149. [CrossRef]

5. Lian, J.J.; Liu, D.; Liu, F. Research progress and frontiers on flood discharge atomization of Chinese high dam projects. J. Hydraul. Eng. 2019, 50, 283-293. [CrossRef]

6. Yuan, H.; Xu, W.L.; Li, R.; Feng, Y.Z.; Hao, Y.F. Spatial distribution characteristics of rainfall for two-jet collisions in air. Water 2018, 10, 1600. [CrossRef]

7. Li, Z. On landslide induced by water-fog from ski-jump energy dissipation of Longyangxia Hydropower Station. Dam Saf. 2001, 3, 17-20.

8. Wang, F.H. Influence of discharging foggy and its protection at Ertan hydropower station. Dam Saf. 2011, 5, 42-46.

9. Gong, J.B.; Pi, J.H. Reflection and countermeasures of "7.19"flood event of Shuibuya dam. Dam Saf. 2018, 0, $20-26$.

10. Lian, J.J.; He, J.L.; Liu, F.; Ran, D.J.; Wang, X.Q.; Wang, C. An improved empirical model for flood discharge atomization and its application to optimize the flip bucket of the Nazixia Project. Int. J. Environ. Res. Public Health 2019, 16, 316. [CrossRef]

11. Peruccacci, S.; Brunetti, M.T.; Gariano, S.L.; Melillo, M.; Rossi, M.; Guzzetti, F. Rainfall thresholds for possible landslide occurrence in Italy. Geomorphology 2017, 290, 39-57. [CrossRef]

12. Prenner, D.; Hrachowitz, M.; Kaitna, R. Trigger characteristics of torrential flows from high to low alpine regions in Austria. Sci. Total Environ. 2019, 658, 958-972. [CrossRef]

13. Ma, H.; Chi, F. Technical progress on researches for the safety of high concrete-faced rockfill dams. Engineering 2016, 2, 332-339. [CrossRef]

14. Lian, J.J.; Li, C.Y.; Liu, F.; Wu, S.Q. A prediction method of flood discharge atomization for high dams. J. Hydraul. Res. 2014, 52, 274-282. [CrossRef]

15. Liu, H.T.; Liu, Z.P.; Xia, Q.F.; Sun, S.K. Computational model of flood discharge splash in large hydropower stations. J. Hydraul. Res. 2015, 53, 576-687. [CrossRef] 
16. Liu, S.H.; Yin, S.R.; Luo, Q.S.; Zhou, L.C. Numerical simulation of atomized flow diffusion in deep and narrow goeges. J. Hydrodyn. Ser. B 2006, 18, 515-518. [CrossRef]

17. Zhang, H. Study on the theory of flood discharging atomization and it's mathematic model in hydropower station. Ph.D. Thesis, Tianjin University, Tianjin, China, 2003.

18. Duan, H.D.; Liu, S.H.; Luo, Q.S.; Huang, W. Rain intensity distribution in the splash region of atomized flow. J. Hydrodyn. Ser. B 2006, 18, 362-366. [CrossRef]

19. Liu, F.; Lian, J.J.; Zhang, X.J.; Li, C.Y. Experimental study of atomization and splashing caused by a ski-jump jet into scour pool. J. Hydroelectr. Eng. 2010, 29, 113-117.

20. Lian, J.; He, J.; Gou, W.; Ran, D. Effects of bucket type and angle on downstream nappe wind caused by a turbulent jet. Int. J. Environ. Res. Public Health 2019, 16, 1360. [CrossRef]

21. Chiang, C.Y.; Yang, T.Y.; Casandra, A.; Lin, S.Y. A study of the splash phenomenon of water drops on wood-Emitted droplet velocity and kinetic energy. Exp. Therm. Fluid Sci. 2017, 88, 444-449. [CrossRef]

22. Papierowska, E.; Mazur, R.; Stańczyk, T.; Beczek, M.; Szewińska, J.; Sochan, A.; Ryżak, M.; Szatyłowicz, J.; Bieganowski, A. Influence of leaf surface wettability on the drop splash phenomenon. Agric. For. Meteorol. 2019, 279, 107762. [CrossRef]

23. Driscoll, H.; Gaviria, S.; Goodwill, S. Analysing splash in competitive diving. Procedia Eng. 2014, 72, $26-31$. [CrossRef]

24. Blocken, B.; Carmeliet, J. A review of wind-driven rain research in building science. J. Wind Eng. Ind. Aerodyn. 2004, 92, 1079-1130. [CrossRef]

25. Verwiebe, C.; Ruscheweyh, H. Recent research results concerning the exciting mechanisms of rain-wind-induced vibrations. J. Wind Eng. Ind. Aerodyn. 1998, 74, 1005-1013. [CrossRef]

26. Burzynski, D.A.; Bansmer, S.E. Droplet splashing on thin moving films at high Weber numbers. Int. J. Multiph. Flow 2018, 101, 202-211. [CrossRef]

27. Schmocker, L.; Pfister, M.; Hager, W.H.; Minor, H.E. Aeration characteristics of ski jump jets. J. Hydraul. Eng. 2008, 134, 90-97. [CrossRef]

28. Castillo, L.G.; Carrillo, J.M.; Bombardelli, F.A. Distribution of mean flow and turbulence statistics in plunge pools. J. Hydroinform. 2017, 19, 173-190. [CrossRef]

29. Fenn, R.W.; Middleman, S. Newtonian jet stability: The role of air resistance. AIChE J. 1969, 15, 379-383. [CrossRef]

30. Lian, J.J.; Dong, Z.; Liu, F.; Liu, D. Experimental study on the influence of low atmospheric pressure on the dynamic pressure. J. Hydroelectr. Eng. 2019, 38, 101-110.

31. Zhang, W.; Zhu, D.Z. Far-field properties of aerated water jets in air. Int. J. Multiph. Flow 2015, 76, $158-167$. [CrossRef]

32. Cai, X.; Wang, X.S.; Liao, G.X. Experimental study on the effects of ambient pressure on spray characteristics of water mist. J. Disas. Prev. Mitig. Eng. 2012, 32, 235-241.

33. Wang, X.; Zhu, P.; Li, Y.; Ni, X.; Fan, M. Effect of low ambient air pressure on spray characteristics of water mist. Exp. Therm. Fluid Sci. 2015, 66, 7-12. [CrossRef]

34. Tsai, P.; Roeland, C.A.V.D.V.; Matthias, V.D.R.; Lohse, D. How micropatterns and air pressure affect splashing on surfaces. Langmuir 2010, 26, 16090-16095. [CrossRef]

35. Mitchell, B.R.; Bate, T.E.; Klewicki, J.C.; Korkolis, Y.P.; Kinsey, B.L. Experimental investigation of droplet impact on metal surfaces in reduced ambient pressure. In 45th Sme North American Manufacturing Research Conference, NAMRC 45, LA, USA; Wang, L., Fratini, L., Shih, A.J., Eds.; Elsevier: Amsterdam, The Netherlands, 2017; Volume 10, pp. 730-736.

36. Latka, A.; Strandburg-Peshkin, A.; Driscoll, M.M.; Stevens, C.S.; Nagel, S.R. Creation of prompt and thin-sheet splashing by varying surface roughness or increasing air pressure. Phys. Rev. Lett. 2012, 109, 054501. [CrossRef]

37. Burzynski, D.A.; Bansmer, S.E. Role of surrounding gas in the outcome of droplet splashing. Phys. Rev. Fluids 2019, 4, 073601. [CrossRef]

38. Tsuchiya, Y.; Horikoshi, C. On the spread of rectangular jets. Exp. Fluids 1986, 4, 197-204. [CrossRef]

39. Isataev, S.I.; Toleuov, G.; Isataev, M.S.; Bolysbekova, S.A. Experimental investigation of three-dimensional turbulent jets issuing from a nozzle with a rectangular output section. J. Eng. Phys. Thermophys. 2016, 89, 391-396. [CrossRef]

40. Tadjfar, M.; Jaberi, A. Effects of aspect ratio on the flow development of rectangular liquid jets issued into stagnant air. Int. J. Multiph. Flow 2019, 115, 144-157. [CrossRef] 
41. Li, Y.; Sun, X.; Zhang, X. Experimental study of the wheeled capsule motion inside hydraulic pipeline. Adv. Mech. Eng. 2019, 11. [CrossRef]

42. Deng, J.; Xu, W.L.; Qu, J.X.; Yang, Y.Q. Influence of aeration on scouring. J. Hydraul. Eng. 2002, 8-13.

43. Dong, Z.Y.; Yang, Y.Q.; Wu, C.G. The influence of aeration on the hydrodynamic pressure of waterjet impinging on the bottom of water cushion. Sci. China (Ser. A) 1994, 24, 431-439.

(C) 2020 by the authors. Licensee MDPI, Basel, Switzerland. This article is an open access article distributed under the terms and conditions of the Creative Commons Attribution (CC BY) license (http://creativecommons.org/licenses/by/4.0/). 